This is the accepted version of:

Ribeiro, Joana Sousa (2017), «Making the "Structures" Speak: Migrant Biographies along

Time», a/b: Auto/Biography Studies, 32(2), 388-390. DOI: 10.1080/08989575.2017.1289025

Published version available at:

https://doi.org/10.1080/08989575.2017.1289025

\title{
Making the "Structures" Speak: Migrant Biographies along Time
}

\author{
by Joana Sousa Ribeiro \\ University of Coimbra \\ (joanasribeiro@ces.uc.pt)
}

Narrative interviews and biographic data collected during a ten-year period among foreign-trained doctors working in Portugal and exploring issues such as migratory experience, job and career paths, citizenship identification, family structure, social mobility, and aspirations indicate the potential of longitudinal studies in the fields of migration and life narrative. The life narratives of the migrants report an interlink between constraints and/or opportunities related to social structures (such as juridical and labor market requirements, language acquisition processes, and participation in reaccreditation programs) and those predicated on agency capabilities.

Considering the lived experience of different migrants' social categories along time - the interviewed migrants are identified at one and the same time as undocumented migrants and overqualified workers, as Portuguese language students, and as recognized skilled professionals - my work suggests that incorporating auto|biographical research methodologies into standard sociological research practices (such as interviews) can reposition the study of migration and migrant lives as a geohistoric biographical process. Indeed, the analysis of the long-term biographic path of migrants considers simultaneously the migrants' lived (hi)story as an intertwined process of resistance, social system (inter)recognition, and (re)distribution in the social ladder. In this vein, a lifenarrative approach posits an important challenge to the structures-versus-agency 
polarization, indicating that over the course of one's life, these are often threaded together rather than set apart.

Studies in sociology are often premised on a dichotomy, positioning structures versus agency (Turner). Social conditionings, institutional order, and historical frames are linked to the former, whereas motives, aspirations, and decision-making behavior are the main focus of the latter. Approaching the above dichotomy using auto|biography methodologies underlines the "biographical structuring" (Fischer-Rosenthal) processes, taking into account the conditions positioning the narration of a life. Hence, a lifenarrative approach suggests the structures-versus-agency counterpositioning to be artificial while concurrently dismantling the identitary approach, even when the scope of identity politics is taken into consideration, as in the case of the "fragmented subject" (Hall) or in the case of "nomadic subject" (Braidotti).

Longitudinal biographic studies offer not only a comprehensive and interpretative understanding of migrant lives but also a diachronic view of migration phenomena as reflected in migrants' categorizations over time, further reinforcing the sociopolitical dimension. A life-narrative approach to migration studies in sociology, then, provides new insights into the ways that migrants incorporate subjectivities, appropriate temporalities, and represent social spatialities when coproducing the narratives of their lives. In doing so, such scholarly work not only allows migrants to narrate their lives but, in fact, makes the social structures "speak."

\section{Disclosure Statement}

No potential conflict of interest was reported by the author.

\section{Funding}

This work was supported by Ministério da Ciência, Tecnologia e Ensino Superior, Fundação para a Ciência e a Tecnologia [grant number SFRH/BD/23548/2005]

\section{ORCID}

Joana Sousa Ribeiro http://orcid.org/0000-0002-5779-7503 


\section{Works Cited}

Braidotti, Rosi. Nomadic Subjects: Embodiment and Sexual Difference in Contemporary Feminist Theory. New York: Columbia UP, 1994. Print.

Fischer-Rosenthal, Wolfram. "Biographical Work and Biographical Structuring in Present-Day Societies." The Turn to Biographical Methods in Social Science. Eds. P. Chamberlayne; J. Bornat, and T. Wengraf. London: Routledge, 2000.

Hall, Stuart. "Cultural Identity and Diaspora." Identity: Community, Culture, Difference. Ed. J. Rutherford. London: Lawrence and Wishart, 1990. 222-37. Print.

Turner, Jonathan. The Structure of Sociological Theory. 5th ed. Belmont: Wadsworth, 1991. Print. 